$\begin{array}{ll}\text { Alanine } & \text { glucagon } \\ \text { amino acids } & \text { gluconeogenesis } \\ \text { branched chain } & \text { hypoglycemia } \\ \quad \text { amino acids } & \text { maple syrup urine } \\ \text { fructose } & \text { disease } \\ \text { genetic disease } & \end{array}$

\title{
Hypoglycemia and Maple Syrup Urine Disease: Defective Gluconeogenesis
}

\author{
MOREY W. HAYMOND, IRENE E. KARL, RALPH D. FEIGIN, DARRYL DEVIVO, AND \\ ANTHONY S. PAGLIARA ${ }^{\prime 381}$ \\ Edward Mallinckrodt Department of Pediatrics and Department of Medicine Washington University School of Medicine, \\ St. Louis Children's Hospital, St. Louis, Missouri, USA
}

\section{Extract}

We are reporting a patient with classic, thiamine-unresponsive maple syrup urine disease (MSUD) associated with severe fasting hypoglycemia. The potential gluconeogenic amino acids, with the exception of glutamate, were markedly depressed. Glutamine and alanine concentrations increased rapidly with the concomitant fall in branched chain amino acids following initiation of a diet free of leucine, isoleucine, and valine. Intravenous glucagon and oral fructose resulted in normal glycemic responses (A76 and A40 mg/100 ml, respectively) and no significant rise in blood lactate or pyruvate.

During two fasting periods \{day 17 and 49) when the branched chain amino acids were elevated, hypoglycemia ensued within $9 \mathrm{hr}$ (47 and $44 \mathrm{mg} / 100 \mathrm{ml}$, respectively). Blood lactate and alanine decreased, and blood ketone bodies rose rapidly with fasting. Plasma insulin was undetectable $(<5 / \mathrm{iU} / \mathrm{ml})$ in the face of hypoglycemia, plasma growth hormone was detectable at all times, and plasma cortisone increased with fasting. At the time of the third fast \{day 58), when branched chain amino acids were in the normal range, blood glucose was maintained for $13 \mathrm{hr}(62 \mathrm{mg} / 100 \mathrm{ml})$. Ketone bodies increased but lactate concentration did not change. Plasma alanine concentration was within the normal range $\left(354 i^{*} u\right)$ and fell during the fast.

Both before and after specific dietary therapy, alanine infusions resulted in no rise in plasma glucose. Plasma insulin remained $<5 \mathrm{piU} / \mathrm{ml}$ during each infusion. With each infusion, regardless of the plasma branched chain amino acid concentrations, there was a transient rise in glutamate and a marked and sustained increase in glutamine. Hyperlactic and hyperpyruvic acidemia were not observed. Concentrations of valine, isoleucine, a-ketoisocaproic acid, a-ketoisovaleric acid, or a-keto-j3-methyl valeric acid 10-fold greater than that present in the patient's plasma or in those reported in other patients with MSUD had little or no effect on the in vitro activity of bovine liver glutamate dehydrogenase, an enzyme which serves as a major link between carbohydrate and amino acid metabolism. In contrast, there was a $22-42 \%$ stimulation of glutamate dehydrogenase activity with concentrations of leucine similar to that found in our patient's plasma.

\section{Speculation}

Hypoglycemia associated with MSUD appears to be related to a defect in gluconeogenesis from amino acids, which cannot be accounted for by abnormalities of the rate- 
limiting gluconeogenic enzymes or hyperinsulinemia. It would appear that there is a preferential shunting of 3-carbon substrates from amino acids into glutamine leading to decreased net oxaloacetate production and impaired gluconeogenesis.

\section{Introduction}

Maple syrup urine disease is associated with a defect in oxidative decarboxylation of the «-keto acids of leucine, isoleucine, and valine. This enzyme is a complex of three interrelated subunits and expression of full activity requires several cofactors [12]. Four variants of this disorder have now been described: classic [4], intermittent $[3,11]$, intermediate [25], and thiamine sensitive [26].

The incidence of hypoglycemia, which is frequently associated with MSUD, is not known, inasmuch as the fasting tolerance in the majority of cases has not been investigated. Donnell et al. [5] demonstrated fasting hypoglycemia and a flat oral glucose tolerance test in a patient with MSUD and improvement of carbohydrate homeostasis with the return of plasma amino acids to normal.

We report a patient with classical MSUD associated with severe fasting hypoglycemia. Investigations to determine the etiology of the hypoglycemia, detailed below, suggest a defect in gluconeogenesis from amino acids.

\section{Case Report}

$S, C$ was an infant weighing $3,090 \mathrm{~g}$, the product of a full term, uncomplicated nonconsanguineous pregnancy of a 20-year-old gravida III, para III Caucasian female. She was well until 5 days of age at which time irritability and feeding difficulty were noted. The patient was admitted to several rural hospitals where poor feeding, a weak, high pitched cry, and increased muscle tone were documented. Skull radiographs purportedly showed separation of all sutures and a ventriculogram, dilated ventricles. Several generalized seizures at 1 week of age prompted therapy with phenobarbital. Seizure activity became more sustained and during a subsequent hospitalization apneic episodes required periodic stimulation and necessitated care in a home for retarded children. She was fed Enfamil (Mead Johnson) every $3 \mathrm{hr}$ by nasogastric tube.

At 3 months of age she was admitted to St. Louis Children's Hospital for further evaluation. Physical examination showed a thin, wasted infant who appeared chronically ill. Vital signs were normal, weight was $3,540 \mathrm{~g}$ and head circumference, $37.5 \mathrm{~cm}$. Positive physical findings included a grade II/VI systolic murmur at the 2nd and 3rd left intercostal space and a liver palpable $3.5 \mathrm{~cm}$ below the right costal margin at the midclavicular line. There was a depressed Moro response, obligatory tonic-neck reflex, and marked lethargy. Nystagmus was observed and at times a darting motion of the eyes similar to opsoclonus was seen. There was bilateral optic atrophy. Limb muscles were rigid and resisted passive stretch. With stimulation the infant assumed a decorticate posture gradually evolving into opisthotonus. Deep tendon reflexes were normal. Transillumination of the frontal area of the skull was increased slightly. Laboratory data included normal electrolytes, calcium, phosphorus, blood urea nitrogen, creatinine, and alkaline phosphatase. Serum glutamic oxaloacetic transaminase (141 U) serum glutamic pyruvic transaminase (104 $\mathrm{U})$, and uric acid $(9.0 \mathrm{mg} / 100$ $\mathrm{ml})$ were elevated on admission but fell to normal levels with dietary therapy.

\section{Hospital Course}

Blood and urine amino acid analysis confirmed the diagnosis of maple syrup urine disease (Table I, Fig. 1). The infant was fed a low protein isocaloric diet while we awaited receipt of the special amino acid mixtures [31] utilized for definitive dietary therapy [27]. On several occasions prior to feedings, asymptomatic hypoglycemia was documented with plasma glucose of $17-26 \mathrm{mg} / 100 \mathrm{ml}$. In an attempt to alleviate the hypoglycemia, food was offered every 2-3 hr. Administration of thiamine, $10 \mathrm{mg} / 24 \mathrm{hr}$ for 4 days, produced no change in her blood amino acid profile. She was placed on a diet devoid of leucine, isoleucine, and valine on the 31st hospital day and within 4 weeks branched chain amino acid concentrations decreased to the normal range (Fig. 1 and Table I). The formula was subsequently supplemented with leucine, isoleucine, and valine [32] to provide minimal requirements for growth. Despite adequate caloric intake of this formula and supportive medical care, the patient did not improve and expired on the 64th hospital day. No postmortem examination was granted by the family. 
Table I. Plasma amino acids during hospital course ${ }^{1}$

\begin{tabular}{|c|c|c|c|c|c|c|c|c|c|c|c|c|}
\hline \multirow{2}{*}{ Amino acid } & \multicolumn{11}{|c|}{ Concentration in MSUD infant on day } & \multirow{2}{*}{$\begin{array}{l}\text { Concentration } \\
\text { in normal] } \\
\text { subjects }\end{array}$} \\
\hline & $0^{*}$ & 5 & 17 & 20 & 24 & $27^{*}$ & 31 & $33^{*}$ & 45 & 49 & 51 & \\
\hline Threonine & 193 & 124 & 149 & 107 & 95 & 123 & 162 & 339 & 447 & 618 & 495 & $152 \pm 20$ \\
\hline Serine & 120 & 82 & 116 & 95 & 90 & 108 & 104 & 156 & 169 & 173 & 125 & $168 \mathrm{db} 11$ \\
\hline Glutamate $^{6}$ & & & 198 & & 110 & 183 & & 127 & 110 & 110 & 122 & $58 \pm 13$ \\
\hline Glutamine $^{6}$ & & & 367 & & 438 & 393 & & 513 & 594 & 410 & 778 & $633 \pm 55$ \\
\hline Proline & 137 & 152 & 187 & 167 & 143 & 136 & 149 & 177 & 296 & 284 & 102 & $150 \pm 10$ \\
\hline Glycine & 165 & 118 & 177 & 168 & 144 & 99 & 171 & 225 & 272 & 308 & 275 & $238 \pm 8$ \\
\hline Alanine $^{6}$ & 67 & 85 & 61 & 68 & 43 & 68 & 68 & 31 & 170 & 196 & 354 & $277 \pm 12$ \\
\hline Valine & 748 & 621 & 533 & 578 & 632 & 618 & 576 & 77 & 82 & 42 & 95 & $177 \mathrm{db} \quad 10$ \\
\hline Methionine $^{7}$ & 238 & 211 & 236 & 205 & 205 & 247 & 173 & 206 & 20 & 44 & 23 & $18 \pm 31$ \\
\hline Isoleucine & 490 & 554 & 503 & 417 & 391 & 579 & 532 & 133 & 87 & 55 & 15 & $71 \pm 7$ \\
\hline Leucine & 3,489 & 3,123 & 3,619 & 3,118 & 3,127 & 3,513 & 3,003 & 1,931 & 582 & 413 & 159 & $115 \mathrm{db} 8$ \\
\hline Tyrosine & 45 & 34 & 58 & 40 & 37 & 47 & 48 & 53 & 55 & 66 & 21 & $69 \pm 7$ \\
\hline Phenylalanine & 46 & 37 & 31 & 48 & 46 & 44 & 67 & 84 & 64 & 109 & 23 & $64 \pm 4$ \\
\hline Lysine & 59 & 36 & 50 & 38 & 27 & 36 & 45 & 47 & 65 & 120 & 46 & 240 it 20 \\
\hline Histidine & 108 & 58 & 73 & 64 & 55 & 46 & 96 & 124 & 119 & 168 & 153 & $132 \pm 19$ \\
\hline Arginine & 35 & 29 & 37 & 21 & 20 & 34 & 34 & 51 & 36 & 49 & 37 & $79 \pm 4$ \\
\hline
\end{tabular}

${ }^{1}$ Concentration of amino acid is expressed in micromoles. MSUD: Maple syrup urine disease.

${ }^{2}$ Day 0-31, Casec $1 \mathrm{~g} / \mathrm{kg}$.

${ }^{3}$ Day $27-31$, thiamine, $10 \mathrm{mg} / 24 \mathrm{hr}$.

${ }^{4}$ Day 33-57 branched chain amino acid-free diet.

${ }^{6}$ Mean \pm SEM for nine normal children after an overnight fast.

${ }_{7}^{6}$ Determined by microfluorometric assay.

${ }^{7}$ Methionine and alloisoleucine.

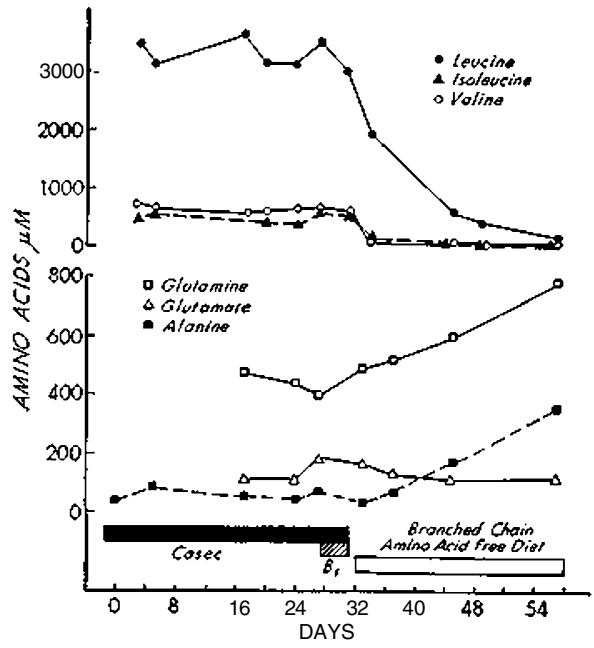

Fig. 1. Effect of therapy on the branched chain amino acids and alanine, glutamine, and glutamate. Casec was given for 31 days at $1 \mathrm{~g} / \mathrm{kg}$, thiamine $(\mathrm{Bj})$ at $10 \mathrm{mg} / \mathrm{kg}$, for 4 days, and the branched chain amino acid-free diet, for 28 days at $2 \mathrm{~g} / \mathrm{kg}$, body wt $/ 24 \mathrm{hr}$. All specimens were obtained at $8 \mathrm{AM}$ on each day $3 \mathrm{hr}$ after her last feeding.

\section{Clinical Study Design}

After obtaining parental consent, the child was admitted to the Clinical Research Center at St. Louis Children's Hospital where several carbohydrate tolerance tests were performed during the course of her therapy to evaluate the etiology of her hypoglycemia.

On days 17, 27, 49, and 58 (when the patient's plasma concentration of leucine were 3,619, 3;127, 413, and $158 \wedge \mathrm{M}$, respectively), intravenous alanine infusions $(250 \mathrm{mg} / \mathrm{kg})$ were performed following a 9-13-hr fast. On day 33, an intravenous glucagon tolerance test $(0.03 \mathrm{mg} / \mathrm{kg})$ was performed after a 2-hour fast. Oral fructose $(500 \mathrm{mg} / \mathrm{kg})$ was administered on day 38 after a 2-hour fast.

\section{Laboratory Methods}

Heparinized blood $(1 \mathrm{ml})$ was drawn at each sampling. Two hundred microliters were immediately precipitated in an equal volume of $3 \mathrm{M}$ perchloric acid. All specimens were placed in ice, centrifuged at $4^{\circ}$, and stored at $-80^{\circ}$. At selected intervals, $1.5 \mathrm{ml}$ blood was obtained for amino acid chromatography. Quantitative amino acid chromatography was performed on an amino acid analyzer [33] using standard methodology [28]. Insulins and growth hormones were determined by immunoassay $[10,22]$ and cortisol by competitive protein binding radioassay [1]. Blood lactate, pyruvate, y3-hydroxybutyrate, acetoacetate, and plasma glucose were determined by modified fluorometric techniques 
$[2,20]$. Plasma alanine was performed by a microfluorometric assay developed in our laboratory [16]. Plasma glutamate was assayed by conversion to a-ketoglutarate in the presence of NAD and glutamic dehydrogenase. The quantitative conversion of NAD to NADH was determined fluorometrically. In a separate aliquot plasma glutamine was converted to glutamate in the presence of glutaminase and the "total" glutamate in the reaction mixture determined. The glutamine present in the sample was calculated by the difference of "total" glutamate (glutamine plus glutamate) and plasma glutamate [17].

In vitro studies of purified bovine liver glutamate dehydrogenase [34] were performed spectrophotometrically by the method of Yielding and Tomkins [30].

\section{Results}

Results of quantitative plasma amino acid determinations are illustrated in Table I. Branched chain amino acids were initially elevated as was the "methionine" peak, the latter presumably as a result of failure to separate methionine from alloisoleucine [27]. In contrast, the potential gluconeogenic amino acids, with the exception of glutamate, were markedly depressed.

Concentrations of the branched chained amino acids and primary gluconeogenic amino acids throughout the patient's hospital course are shown in Fig. 1. Glutamine and alanine concentrations increased rapidly with the concomitant fall in the branched chain amino acids after initiation of a diet free of leucine, isoleucine, and valine.

Glucose, alanine, glutamine, and lactate concentrations after intravenous glucagon, along with values obtained from nine normal children after an overnight fast, are shown in Figure 2. The glucose, lactate, and glutamine responses were similar to those observed in normal subjects. Alanine was markedly depressed, as noted above, and rose slightly with glucagon administration as opposed to the $70 \mathrm{fj} M$ fall in normal subjects. Oral fructose (Fig. 3) resulted in a normal glycemic response (A40 mg/100 ml) with no significant rise in blood lactate.

The effects of fasting on substrate and hormone levels are found in Table II. During the first two fasts (days 17 and 49) when the branched chain amino acids were elevated, hypoglycemia ensued within $9 \mathrm{hr}$ (plasma glucose 47 and $44 \mathrm{mg} / 100 \mathrm{ml}$, respectively). Blood lactate decreased with fasting. Alanine levels, which were markedly depressed at the onset of the fast,

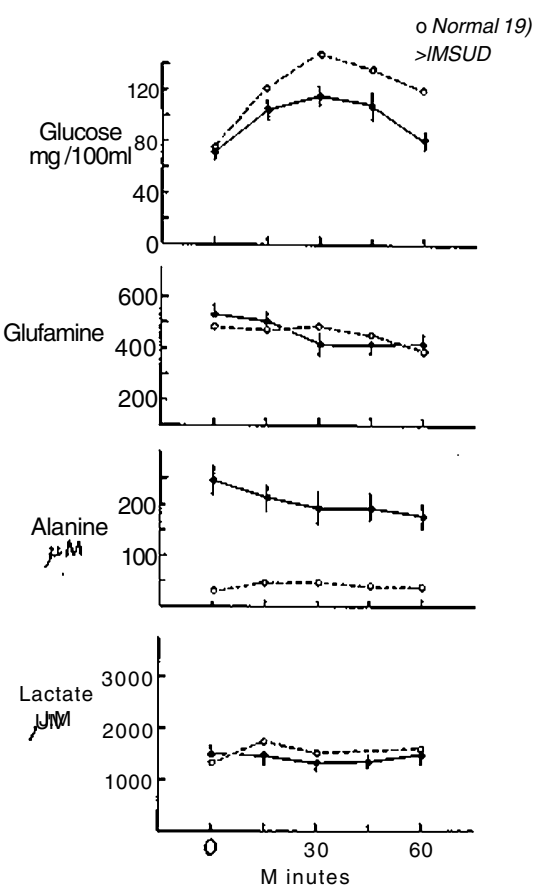

Fig. 2. Effects of glucagon infusion on plasma glucose, alanine, glutamine, and blood lactate. Intravenous glucagon $0.03 \mathrm{mg} / \mathrm{kg}$, body wt, was given to the patient on day 33 after a 2-hr fast and compared with the mean \pm SEM response in nine normal children following an overnight fast. MSUD: Maple syrup urine disease.

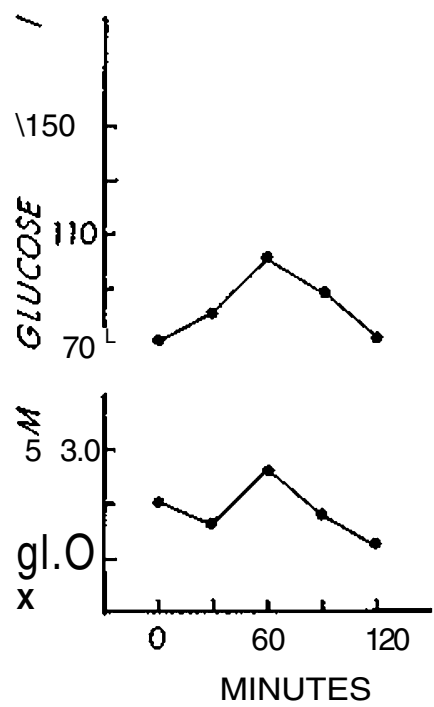

Fig. 3. Effect of oral fructose challenge on plasma glucose and lactate. Oral fructose, $500 \mathrm{mg} / \mathrm{kg}$, body wt, after a 2 -hr fast was given on day 38 .

also decreased. Insulin was undetectable in the face of hypoglycemia and plasma cortisol increased with fast- 
Table II. Effects of fasting on substrate and hormone levels

\begin{tabular}{|c|c|c|c|c|c|c|c|c|c|}
\hline & $\begin{array}{c}\text { Fasting, } \\
\mathrm{hr}\end{array}$ & $\begin{array}{l}\text { Plasma } \\
\text { glucose, } \\
\mathrm{mg} / 100 \mathrm{ml}\end{array}$ & $\begin{array}{l}\text { Blood lactate, } \\
\mathrm{mM}\end{array}$ & $\begin{array}{c}\text { Plasma } \\
\text { alanine, } \\
i M .\end{array}$ & $\begin{array}{l}\text { Blood } / 3-\mathrm{OH}- \\
\text { butyrate and } \\
\text { acetoacetate, } \\
\mathbf{k N} .\end{array}$ & $\begin{array}{l}\text { Plasma } \\
\text { insulin, } \\
/ \mathrm{xU} / \mathrm{ml}\end{array}$ & $\begin{array}{c}\text { Plasma } \\
\text { cortisol, } \\
\text { /xg/100 ml }\end{array}$ & $\begin{array}{c}\text { Plasma } \\
\text { growth } \\
\text { hormone, } \\
\mathrm{ng} / \mathrm{ml}\end{array}$ & $\begin{array}{c}\text { Plasma } \\
\text { leucine, JM }\end{array}$ \\
\hline \multicolumn{10}{|l|}{ Fast I, day 17} \\
\hline \multirow[t]{2}{*}{ Beginning } & 0 & 151 & 2.21 & 76 & .120 & 20 & 2.7 & 92 & 3,490 \\
\hline & 3.0 & 71 & & 61 & $\cdot 212$ & $<5$ & & 25 & \\
\hline End of fast & 9.0 & 47 & 1.40 & 54 & 2,950 & $<5$ & 15.2 & 23 & \\
\hline \multicolumn{10}{|l|}{ Fast II, day 49} \\
\hline Beginning & 2.0 & 55 & 2.54 & 196 & 122 & 14 & & 22 & 413 \\
\hline End of fast & 9.5 & 44 & 1.75 & 124 & 1,138 & $<5$ & & 11 & \\
\hline \multicolumn{10}{|l|}{ Fast III, day 58} \\
\hline Beginning & 2.0 & 80 & 0.80 & 354 & 145 . & $<5$ & 2.6 & 13 & 160 \\
\hline End of fast & 13.5 & 62 & 1.03 & 207 & 1,550 & $<5$ & 20.8 & 17 & \\
\hline
\end{tabular}

ing. Ketone bodies (/3-hydroxybutyrate and acetoacetate) rose rapidly. Growth hormone was detectable at all times. At the time of the third fast (day 58), when branched chain amino acids were in the normal range (leucine $160 \mathrm{yM}$ ), blood glucose was maintained at more than $60 \mathrm{mg} / 100 \mathrm{ml}$ for $13 \mathrm{hr}$. Ketone bodies increased but lactate concentration did not change. Plasma alanine concentration was within the normal range $\left(354^{\wedge} \mathrm{M}\right)$ and fell during the fast. Changes in insulin, growth hormone, and cortisol were similar in direction and magnitude to that of previous fasts.

Regardless of the plasma branched chain amino acid concentration and despite therapy, no differences were observed in the patient's abnormal response to infused alanine. Thus, results for all four alanine tolerances were meaned and compared with similar studies in six normal children after an overnight fast (Fig. 4). Plasma glucose decreased $5 \mathrm{mg} / 100 \mathrm{ml}$ as compared with a $20 \mathrm{mg} / 100 \mathrm{ml}$ rise observed in normal subjects within $30 \mathrm{~min}$ of infusion. There was a transient increase in glutamate and a marked and sustained rise in glutamine. Hyperlactic and hyperpyruvicacidemia were not observed. Growth hormone was significantly elevated above controls before the infusion and no significant change occurred as compared with the significant rise $(2.3 \pm 1.0$ to $18.5 \pm 4.6 \mathrm{ng} / \mathrm{ml})$ observed in controls within $45 \mathrm{~min}$ after infusion. Plasma insulin was $<5, \mathrm{u}, \mathrm{U} / \mathrm{ml}$ during each test (data not shown).

The obvious abnormalities observed in plasma levels of glutamate and glutamine after all alanine infusions prompted studies utilizing a purified preparation of bovine liver glutamate dehydrogenase, an enzyme which serves as a major link between carbohydrate and amino acid metabolism [9] (Fig. 5). The effects of the addition of branched chain amino acids, their a-keto acids, the patient's plasma, and plasma from a normal subject upon glutamate dehydrogenase activity in vitro are shown in Table III. When the concentrations of valine, isoleucine, a-keto isocaproic acid, a-keto isovaleric acid, or a-keto-^-methyl valeric acid were 10 -fold greater than that of the patient's plasma or those reported in patients with MSUD [6], little or no increased enzyme activity occurred. In contrast, there was a $22-42 \%$ stimulation of glutamate dehydrogenase activity with concentrations of leucine similar to that found in our patient. The patient's serum also increased the activity of this enzyme $27 \%$ above that of the control plasma.

\section{Discussion}

In MSUD, hypoglycemia could be secondary to stimulated insulin release, as seen in patients with leucinesensitive hypoglycemia [15]. Hyperinsulinemia was not a causitive factor in this patient because there was little detectable insulin and marked ketonemia at the time of hypoglycemia. Hypopituitarism or adrenal insufficiency could not account for the hypoglycemia, inasmuch as adequate growth hormone and cortisol levels were present under basal and fasting conditions (Table II).

The normal increase in blood glucose after glucagon administration (Fig. 2), without a concomitant increase in blood lactate or pyruvate, provides evidence that the patient was capable of storing and releasing glycogen normally [23]. Glutamine and alanine concentrations fell in normal children with glucagon administration, which implies increased hepatic gluconeogenesis. A similar fall in glutamine was observed in our patient, but alanine concentrations were very low and did not change. Glucagon tolerance tests in other patients with MSUD also have shown normal glucose responses [5]. Fructose administration also resulted in 
an increase in glucose without lactate accumulation, suggesting that her gluconeogenic pathway from the level of the triose phosphates was intact (Fig. 3).

Cahill and co-workers [7, 21] have provided evidence that alanine and, possibly, glutamine, are the primary gluconeogenic amino acid substrates utilized by fasting man. Increased concentrations of branched chain amino acids in this patient were associated with marked depressions of her gluconeogenic amino acids (Fig. 1 and Table I). Although data provided in pre-

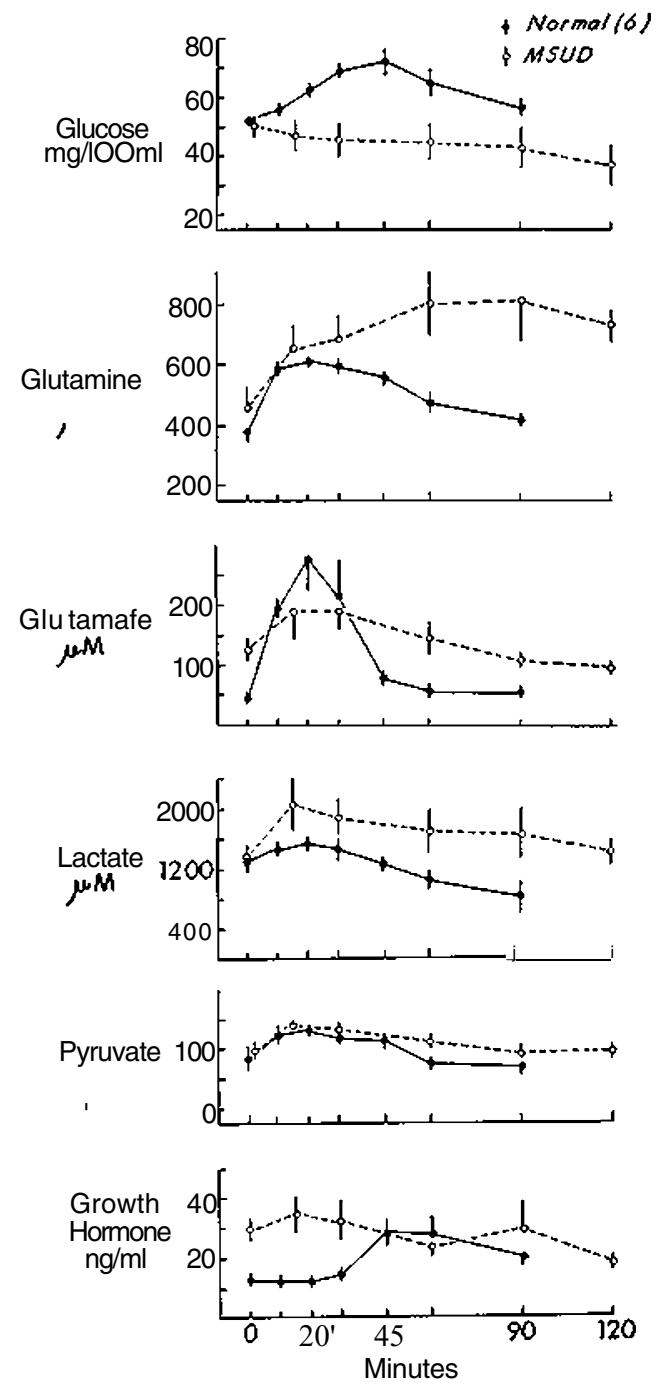

Fig. 4. Response to infused alanine. Alanine $250 \mathrm{mg} / \mathrm{kg}$, body wt, was infused over a $5 \mathrm{~min}$ interval in six normal children after overnight fast and the patient on days 17, 27, 49, and 58 after a 9 -13-hr fast both before and after specific dietary therapy. Because no qualitative differences were observed in the patient's responses to infused alanine all test results were meaned. Each point represents the mean \pm SEM. MSUD: Maple syrup urine disease.

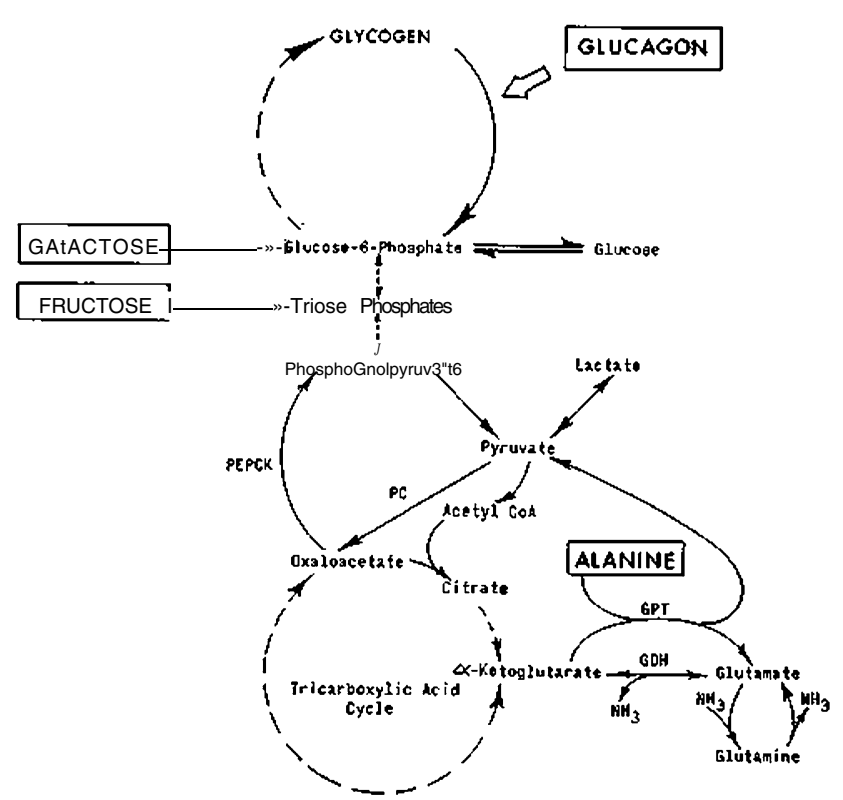

Fig. 5. Abbreviated schema of entrance of gluconeogenic substrates into the gluconeogenic pathway and tricarboxylic acid cycle. GPT: Glutamate pyruvate transaminase; $G D H$ : glutamate dehydrogenase; $P C$ : pyruvate carboxylase; $P E P C K$ : phosphoenolpyruvate carboxykinase.

Table III. Effect of the branched chain amino acids, their a-keto acids, and plasma of a normal control subject and the patient on activity of purified bovine glutamate dehydrogenase in vitro

\begin{tabular}{lcc}
\hline & $\begin{array}{c}\text { Tested } \\
\text { substance, } \\
\mathbf{m} \mu \mathbf{s} / \mathbf{h} .\end{array}$ & $\begin{array}{c}\text { Stimulation } \\
\text { above control, } \\
\boldsymbol{\%}\end{array}$ \\
\hline Control & 0 & \\
a-Keto isocaproic & 2,000 & 8 \\
a-Keto isovaleric & 2,000 & 8 \\
a-Keto-/3-methyl valeric & 2,000 & 0 \\
Isoleucine & 2,000 & $\mathbf{0}$ \\
Valine & 2,000 & 6 \\
Leucine & 2,000 & 54 \\
& 1,000 & 50 \\
& 500 & $\mathbf{4 2}$ \\
Control plasma, 50 jul & 100 & $\mathbf{2 2}$ \\
Patient plasma & $12.5^{1}$ & $\mathbf{2 7} \pm \mathbf{5}^{\mathbf{3}}$ \\
\hline
\end{tabular}

${ }^{1}$ Calculated leucine content in $50 / J L \mid$ of normal plasma.

${ }^{2}$ Calculated leucine content in 50 jul of patient's plasma (3.490 inn).

${ }^{3}$ Mean \pm SEM (four determinations) expressed as percentage stimulation above control plasma.

vious reports of MSUD also have demonstrated these findings, no comment has been made concerning the relationship of the gluconeogenic amino acids to the hypoglycemia [4, 27]. Her hypoglycemia could have 
been accounted for by a deficiency of alanine as reported in patients with ketotic hypoglycemia [23]; however, when she was provided with sufficient gluconeogenic substrate in the form of intravenous alanine, no glycemic response was elicited (Fig. 4).

In the normal fasting child, infusion of alanine is followed by a rapid rise in blood glucose and growth hormone with a minimal increase in blood lactate and pyruvate. Plasma glutamate and glutamine also increase transiently (Fig. 4). For a gluconeogenic substrate below the level of phosphoenolpyruvate to result in glucose synthesis (Fig. 5), net oxaloacetate production is required [18, 19]. The precise pathways involved in the conversion of alanine to glucose are unknown. It is presumed that alanine is transaminated with a-ketoglutarate to glutamate and pyruvate by glutamic-pyruvate transaminase. The pyruvate is then carboxylated via pyruvate carboxylase to oxaloacetate. For every mole of alanine transaminated, a mole of a-ketoglutarate is consumed, which depletes the tricarboxylic acid (TCA) cycle of substrates and thus $a$ priori would decrease the net production of oxaloacetate. To maintain substrate homeostasis in the TCA cycle there must be conversion of glutamate back to a-ketoglutarate (or other intermediates) and production of ammonia. Since glutamate dehydrogenase serves as a central enzyme in carbohydrate and amino acid metabolism, it has been postulated that changes in activity of this enzyme could affect both protein synthesis and gluconeogenesis [9].

When the branched chain amino acids were elevated, concentrations of glutamate were increased, whereas glutamine and all the other gluconeogenic amino acids were decreased. Alanine administration, in the presence of hypoglycemia, was not accompanied by a glycemic response. A normal transient increase in pyruvate and lactate occurred; however, the glutamine response was abnormal in that there was a rapid and sustained increase (Fig. 4). Although the basal concentration of glutamate was increased (two- -threefold above normal), the absolute increase above pre-infusion levels of this amino acid was similar to that observed in normals. Transamination and utilization of administered alanine can be assumed because of the transient increase in pyruvate and lactate and the rise in glutamate and glutamine. Sustained and marked elevations of lactate and pyruvate are seen in patients with defined gluconeogenic enzymatic defects \{i.e., fructose 1,6-diphosphatase [24] and glucose 6-phosphatase [29]) after alanine administration. Similarly, a de- fect in phosphoenolpyruvate carboxykinase or pyruvate carboxylase theoretically should be associated with hyperlacticacidemia and hyperpyruvicacidemia with an increased gluconeogenic load. In our patient, because there was no sustained increase in blood lactate or pyruvate, it is suggested that there is no defect in the rate-limiting gluconeogenic enzymes.

It would appear from our data that there existed a preferential shunting of 3-carbon substrates into glutamine, thereby preventing reimbursement of the TCA cycle. This would ultimately lead to decreased net oxaloacetate production and impaired gluconeogenesis. The precipitous and sustained rise in glutamine and abnormally elevated glutamate levels may reflect inhibition of normal glutamine and glutamate metabolism. The elevated glutamine could result from secondary stimulation of glutamine synthetase or conversely, end-product inhibition of glutaminase [13]. However, this would not explain the elevated glutamate levels. It has been demonstrated that leucine stimulates glutamate dehydrogenase activity in vitro [30]. We confirmed this finding utilizing both the patient's plasma and exogenous leucine at concentrations similar to those found in our patient. Greenberg and Reaven [14] demonstrated that hepatic gluconeogenesis from alanine was inhibited by leucine in vitro. Thus, it would appear that elevated leucine concentrations may impair gluconeogenesis both in vivo and in vitro.

When the patient's branched chain amino acids were corrected by specific dietary therapy, the concentrations of gluconeogenic amino acids in plasma returned to the normal range (Fig. 1). This was accompanied by an increased ability to sustain a 13-hour fast without hypoglycemia; however, the patients response to infused alanine did not improve. The findings of normal plasma branched chain amino acid concentrations do not necessarily imply normal intracellular concentrations and secondary enzyme inhibition may have persisted.

Despite specific dietary therapy and supportive medical management, the patient's clinical condition deteriorated, obviating further studies. Additional speculation in regard to the etiology of hypoglycemia in MSUD is not warranted at this time. However, it would appear that an enzyme or enzymes regulating TCA cycle homeostasis could result in decreased net 
oxaloacetate production and secondary defective gluconeogenesis from amino acids.

\section{Summary}

A 3-month-old severely retarded Caucasian female with classical MSUD associated with severe hypoglycemia is presented. Investigations performed to determine the etiology of the hypoglycemia suggest a deficit in gluconeogenesis from amino acids.

\section{References and Notes}

1. Beitins, I. Z., SHAW, M. H., KOWARSKI, A., AND MigeON, C. J.: Comparison of competitive protein binding radioassay of cortisol to double isotope dilution and Porter-Silber methods. Steroids, 15: 765 (1970).

2. CAHILl, J. F., JR., HERRERA, M. G., MORGAN, A. P., SOELDNER, J. S., STEINKE, J., LEVY, P. L., REICHARD, G. H., JR., AND KIPNIS, D. M.: Hormonal-fuel interrelationships during fasting. J. Clin. Invest., 45: 1751 (1966).

3. DANCIS, J., HUTZLER, J., AND ROKKONES, T.: Intermittent branched-chain ketonuria variant of maple-syrup urine disease. New Engl. J. Med., 276: 84 (1967).

4. DANCIS, J., AND LEVITZ, M.: Abnormalities of branched-chain amino acid metabolism. In: J. B. Stanbury, J. B. Wyngaarden, and D. S. Fredrickson: The Metabolic Basis of Inherited Disease, Ed. 3, p. 426 (McGraw-Hill, New York, 1972\}.

5. DONNELl, G. N., LIEBERMAN, E., SHAW, K. N. F., AND KoCH, R.: Hypoglycemia in maple syrup urine disease. Amer. J. Dis. Child., 113: 60 (1967).

6. DREYFUS, P. M., AND PRENSKY, A. L.: Further observations on the biochemical lesion in maple syrup urine disease. Nature, 214: 276 (1967).

7. FElig, P., OWENS, O. E., WAhren, J., AND CAhill, J. F., JR.: Amino acid metabolism during prolonged starvation. J. Clin. Invest., 48: 584 (1969).

8. FElig, P., POZEFSKY, T., MARliss, E., AND CAHILl, J. F., JR.: Alanine keyrole in gluconeogenesis. Science, 167: 1003 (1970).

9. FRIEDEN, C: Glutamate dehydrogenase. V. The relationship of enzyme structure to the catalytic function: J. Biol. Chem., 238: 3286 (1963).

10. GLICK, S. M., ROTH, J., YALOW, R. S., AND BERSON, S. A.: Immunoassay of human growth hormone in plasma. Nature, 199: 784 (1963).

11. GOEdDE, H. W., LANGenBeCK, D., BRACKertz, D., Keller, W., ROKKONES, T., HALVORSEN, S., KIIL, R., AND MERTON, B.: Clinical and biochemical genetic aspects of intermittent branched-chain ketoaciduria. Acta Paediat. Scand., 59: 83 (1970).

12. GOEDDE, H. W., AND KELLER, W. In: W. L. Nyhan: Amino Acid Metabolism and Genetic Variation, p. 191. (McGrawHill, New York, 1967).

13. GOLDSTEIN, L.: Relation of glutamate to ammonia production in the rat kidney. Amer. J. Physiol., 210: 661 (1966).

14. GREENBERG, R., AND REAVEN, G.: The effect of L-leucine on hepatic glucose formation. Pediatrics, 37: 934, 1966.

15. GRUMBACH, M. M., AND KAPLAN, S. L.: Amino acid and keto acid-induced hyperinsulinism in the leucine-sensitive type of infantile and childhood hypoglycemia. J. Pediat., 57: 346 (1960).

16. KARL, I. E., PAGliARA, A. S., AND KIPNIS, D. M.: A microfluorometric enzymatic assay for the determination of alanine and pyruvate in plasma and tissue. J. Lab. Clin. Med., 80: 434, 1972.

17. KARL, I. E., PAGLIARA, A. S., AND KIPNIS, D. M.: A microfluorometric enzymatic assay for the determination of glutamine and glutamate in plasma and tissue (manuscript in preparation).

lg. KREBS, H. A.: The regulation of the release of ketone bodies by the liver. Advan. Enzyme Regul., 4: 339 (1966).

19. KREBS, H. A., GASCOYNE, T., AND NOTTON, B. M.: Generation of extra mitochondrial reducing power in gluconeogenesis. Biochem. J., 102: 275 (1967).

20. LOWRY, O. H., PASSONNEAU, J. V., HESSElBERGER, F. X., AND SCHULZ, D. IV.: Effect of ischemia on known substrates and cofactors on the glycolytic pathway in brain. J. Biol. Chem., 239: 18 (1964).

21. MARLISS, E. B., AOKI, T. T., POZEKFSKY, T., MOST, A. S., AND CAHILL, G. F., JR.: Muscle and splanchnic glutamine and glutamate metabolism in post absorptive and starved man. J. Clin. Invest., 50: 814 (1971).

22. MORGAN, C. A., AND LAZAROW, A.: Immunoassay of insulin: Two antibody system. Diabetes, 12: 115 (1963).

23. PAGliara, A. S., KARL, I. E., DEVIVO, D. C, FEIGIN, R. D., AND KIPNIS, D. M.: Hypoalaninemia: A concomitant of ketotic hypoglycemia. J. Clin. Invest., 51: 1440 (1972).

24. PAGliara, A. S., KARL, I. E., KeAting, J. P., BROWN, B. I., AND KIPNIS, D. M.: Hepatic fructose 1,6 diphosphatase deficiency: A cause of lactic acidosis and hypoglycemia in infancy. J. Clin. Invest., 51: 2115, 1972.

25. SCHULMAN, J. D., LUSTBERG, T. J., KENNEDY, J. L., MuSELES, M., AND SEEGMILLER, J. E.: A new variant of maple syrup urine disease (branched chain ketoaciduria). Amer. J. Med., 49: 118(1970).

26. SCRIVER, C. R., MACKENZIE, S., ClOW, C. L., AND DELVIN, E.: Thiamine-responsive maple syrup urine disease. Lancet, $i$ : 310 (1971).

27. SNYDERMAN, S. E., NORTON, P. M., ROITMAN, E., AND HOLT, L. E., JR.: Maple syrup urine disease, with particular reference to dietotherapy. Pediatrics, 34: 454 (1964).

28. Technicon Autoanalyzer Methodology, Technicon Chromatography Corporation, Chauncey, New York, 1960.

29. Unpublished data.

30. YIELDING, K. L., AND TOMKINS, G. M.: An effect of L-leucine and other essential amino acids on the structure and activity of glutamic dehydrogenase. Proc. Nat. Acad. Sci. U.S.A., 47: 983 (1961).

31. MED-71004, General Biochemicals, Chagrin Falls, Ohio.

32. Casec, Mead Johnson, Evansville, Ind.

33. Technicon Chromatography Corporation, Chauncey, N. Y.

34. Sigma Chemical Company, St. Louis, Mo.

35. We would like to thank Mr. Thomas Howard and Mr. Dennis Strobel for their excellent technical assistance, and Mrs. Judy Rodgers for the typing of the manuscript. We are indebted to Dr. Philip R. Dodge for his critical review of the manuscript.

36. Dr. M. W. Haymond is a Scharff Fellow in Pediatric Endo- 
crinology. Dr. Feigin is a recipient of Research Career Development Award no. 1K.04AI46206 from the National Institute of Allergy and Infectious Disease, United States Public Health Service. Dr. A. S. Pagliara is an Investigator, Howard Hughes Medical Institute.

37. This research was supported by Research Grant no. HD AM
06355-01, National Institutes of Health, and by Grant no. RR-0036, General Clinical Research Centers Program,

38. Requests for reprints should be addressed to: ANTHONY S. PAGLIARA, M.D., 500 S. Kingshighway, St. Louis, Mo. 63110 (USA).

39. Accepted for publication December 20, 1972. 